\title{
Fishing through time: population dynamics of plaice (Pleuronectes platessa) in the Kattegat-Skagerrak over a century
}

\author{
Massimiliano Cardinale $\cdot$ Jacob Hagberg • \\ Henrik Svedäng • Valerio Bartolino · Todd Gedamke • \\ Joakim Hjelm · Patrik Börjesson · Fredrik Norén
}

Received: 13 March 2009/Accepted: 24 June 2009/Published online: 17 September 2009

(C) The Society of Population Ecology and Springer 2009

\begin{abstract}
Over the past century, advances in technology and historical events such as climate change have resulted in significant changes in the exploitation pattern, population sizes and the potential yield of fish stocks. These variations provide contrast in the data that improves our knowledge on population dynamics and our ability to develop management strategies for long-term sustainable exploitation. In this study, we use a standardized scientific trawl survey to obtain a historical time series (1901-2007) of relative abundance, recruitment and size structure for
\end{abstract}

Electronic supplementary material The online version of this article (doi:10.1007/s10144-009-0177-x) contains supplementary material, which is available to authorized users.

M. Cardinale $(\bowtie) \cdot$ H. Svedäng $\cdot$ J. Hjelm

Institute of Marine Research,

Swedish Board of Fisheries,

PO Box 4, Lysekil, Sweden

e-mail: massimiliano.cardinale@ fiskeriverket.se

J. Hagberg

Swedish Environmental Protection Agency,

Valhallavägen 195, Stockholm, Sweden

\section{P. Börjesson}

PB MiljöData, Rosviksgatan 12, 45330 Lysekil, Sweden

F. Norén

N-Research, Rosviksgatan 12, 45330 Lysekil, Sweden

V. Bartolino

Department of Animal and Human Biology,

University of Rome La Sapienza,

v.le dell'Università 32, 00185 Rome, Italy

T. Gedamke

National Oceanic and Atmospheric Administration,

National Marine Fisheries Service,

75 Virginia Beach Drive, Miami, FL 33149, USA plaice in the Kattegat-Skagerrak. Our work extends the available time series by more than 80 years so that the evaluation of trends is more informative than is possible from the current assessment. We show that the current adult biomass is approximately $40 \%$ of the maximum observed at the beginning of the century and during the 1960s. The average maximum individual length has been reduced by $10 \mathrm{~cm}$ over the studied time period. An analysis of trends in mean length indicates that fishing mortality was variable during the first half of the century and has increased steadily over the past 20 years. Recruitment has been the highest on record during recent years, suggesting that the alleged link between coastal environmental degradation and juvenile survival is of low importance. The overall findings of our work will provide managers with a historical perspective on the population dynamics of the stock, which will support the long-term management of plaice in the Kattegat-Skagerrak.

Keywords Historical · Pre-massive exploitation period · Population dynamic $\cdot$ Research survey

\section{Introduction}

Historical trends of abundance, size structure and distribution are crucial elements for estimating biological reference points used for the restoration and long-term management of exploited fish populations (Jackson et al. 2001). A historical perspective provides valuable information to both scientists and policy makers on the potential productivity of marine ecosystems (Rosenberg et al. 2005). Fluctuation in fish abundance depends not only on the effects of fishing, but also on the stochastic variation observed in key processes, such as recruitment, predation and migration (Fromentin and 
Kell 2007), which may all be linked to environmental fluctuations (Bailey 2000; Köster et al. 2005). Detailed knowledge is required on the stock status prior to or during the development of the industrialized fisheries, which occurred between the end of the 19th and the start of 20th centuries (Mackinson 2002; Lotze and Milewski 2004), to disentangle the effects of exploitation from the natural dynamics of the system. In this respect, a better understanding of the virgin or un-fished conditions (e.g., biomass, mean length, age structure and spatial distribution) would greatly enhance the ability to develop effective long-term management strategies (Roberts 2007). Large efforts have recently been made to compile and analyze historical trends in fish populations (cf. Ojaveer and MacKenzie 2007). The results of those studies, which are based on long time series of data, are valuable for a broader understanding of the dynamics of exploited fish populations and their relationship to the environment.

Exploited commercial species in the north Atlantic were first assessed in the second half of the 20th century, soon after the Second World War (WWII; Myers and Worm 2003; ICES 2007). However, the exploitation of several commercial species began in the Middle Ages in the Skagerrak and Kattegat area (hereafter referred to as Kattegat-Skaggerak) (Andersson 1954). In this area, a semi-industrialized longline fishery targeting halibut, ling, cod, haddock and skates had already developed in the 19th century (Hasslöf 1949), and the Swedish longline fishery in the Skagerrak-Kattegat was well developed at this time (Hasslöf 1949). This led to partial overfishing in the area, and the fishery started to exploit more distant fishing grounds such as those along the Norwegian trench and around the Shetlands. Trawling was introduced on a broad scale between the end of the 19th century and the start of the 20th century, and this sector of the fleet was larger than the longliners before the First World War (Andersson 1954). Attempts were made during the 19th century to introduce sailing trawlers to the Swedish west coast, but without success. In contrast, trawling using motor-equipped fishing vessels was adopted rapidly by the fishing industry at the start of the 20th century. This technological revolution led to a renewed focus on the Kattegat and Skagerrak and diversification of the fishery. Concurrently, fishery biology was developed as a separate scientific branch with connections to Sweden (one of the founder of ICES was the Swedish oceanographer Otto Pettersson). Fishery biology studies were therefore regarded as of national interest, and scientific monitoring trawling schemes were introduced along with motor trawling to the fishery. The major restriction in the demersal fishery was the amount of suitable trawling areas.

The distribution of the scientific hauls in this study reflects the major fishing areas for the demersal fishery in the Skagerrak and Kattegat. Additional fishing areas have successively become available because of better navigational instruments. This may have led to higher efficiency, raising the fishing mortality for a number of species, but it should not be regarded as a progressive change in fishing pattern. Demersal fishing in the Skagerrak-Kattegat can thus be considered as being performed in a similar way for the last 100 years or so, although technological advancements have led to higher efficiency and lower costs. WWI and WWII led to a reduction in fishing activity in the Skagerrak-Kattegat, although to a lesser extent than in the North Sea, especially during WWI. The two world wars are the only events that led to temporarily changed fishing patterns. There is no evidence of economic crises or legislation that changed or diminished the fishing activity in a detectable way. Unfortunately, no quantitative data exist on the development of the effective effort in the area. Fishing mortality at the beginning of the last century is assumed to have been relatively low for plaice (Pleuronectes platessa), which is mainly caught with trawl or Danish seines (Rijnsdorp and Millner 1996; Mackinson 2002). Nevertheless, the start of the 20th century represents only a waypoint rather than a baseline from which it is possible to fully estimate the decline of fish populations in the North Sea considering the semi-industrialized exploitation that started at least a century earlier (Roberts 2007).

The Swedish Institute of Marine Research and its predecessors initiated national scientific trawl surveys in the Kattegat-Skagerrak in 1901. Surveys in this area have been performed on almost an annual basis ever since. This database represents an opportunity to estimate population size, recruitment and size structure extending back to the start of the 20th century. This greatly extends the available time series of data (ICES 2007) and provides insights into the dynamics of plaice in this area and an opportunity to redefine the management baseline for this stock.

In this study, we have used standardized survey trawl catch data to obtain comparable catch per unit effort (CPUE) values from 1901 to 2007. This time series of plaice stock adult biomass, recruitment and size distribution will provide a new perspective of the stock in relation to a situation at presumably much lower levels of exploitation and provide a baseline for long-term management of the plaice stock in the Kattegat-Skagerrak.

\section{Materials and methods}

Available data

A database was established by compiling all known archived otter trawl surveys that were carried out in the Kattegat-Skagerrak from 1901 to 2007 by the Institute of 
Marine Research and its predecessors. A number of different types of bottom trawls and research vessels were utilized over the last century, due in part to advances in technology. Characteristics of the approved trawls and statistics of the hauls are summarized in Table A1 in the Electronic Supplementary Material (ESM). Since 1974, most surveys have been conducted by the Swedish vessel Argos within the IBTS (International Bottom Trawl Survey; ICES 1992), although national trawl surveys have still been carried out. An extensive coastal trawl survey was initiated in 2001, conducted by the vessel Ancylus, which included the Kattegat and the eastern coastal part of the Skagerrak.

Trawl station information included date, haul duration, towing speed, setting and hauling position (latitude and longitude; those were reconstructed from detailed fishing area information included in the archived haul information prior to the use of a Geographical Position System) and depth (meters). Hauls used in the analysis were conducted exclusively during daylight hours. For each haul, the number of individuals and the total length $(\mathrm{cm})$ of each plaice were recorded. For some hauls ( $2.8 \%$ of the total) length-frequency data were not available, although the total number of fish caught was reported. For those hauls and for the CPUE calculations, the length frequency distribution, as estimated in the same year, season and area was used to calculate the number of fish per length class $(1 \mathrm{~cm})$ in the haul. However, hauls when length-frequencies were not recorded were excluded from the length analyses. Landings data from the Kattegat-Skagerrak were collated from official ICES sources (http://www.ices.dk).

\section{Standardization of catch per unit effort (CPUE)}

The first step in standardizing CPUE was to produce a bottom swept area abundance estimate for each haul (Rijnsdorp et al. 1996; Daan et al. 2005). We standardized each haul to a swept area of $0.89 \mathrm{~km}^{2}$ to account for different gear widths, tow times and tow speeds. Such a procedure is usually defined as "area-swept abundance estimation" (Harley and Myers 2001), and in this study it corresponds to the abundance of fish caught in $1 \mathrm{~h}$ trawling a swept area of $0.89 \mathrm{~km}^{2}$ (see ESM for details). The horizontal opening of a trawl is usually estimated as $2 / 3$ of the length of the trawl headline (Rijnsdorp et al. 1996). The part of the horizontal opening that is due to the sweeps was added to that of the headline by estimating the horizontal distance between the trawl doors (cf. Rijnsdorp et al. 1996). The distance between the doors and the horizontal opening of the sweeps depends on the sweep length, but also on the angle between the sweep/headline and the tow direction. Here, we used the average angle $\left(49^{\circ}\right)$, as measured for the RV Argos GOV-trawl ["Grand Ouverture Vertical”; ESM,
ICES (1992)] to estimate the horizontal opening for all those survey trawls that used sweeps. When trawling speed was not available for a haul, the average speed for the vessel and year concerned was used (Table A1).

We performed an experiment to compare the Argos GOV1 and the Ancylus Nephrops trawl to test our expected trawl productivity based on "area-swept abundance estimates" (Svedäng 2007). The experiment was based on 31 parallel hauls in 2004 and 2007 in the Kattegat-Skagerrak. The CPUE-values for Argos GOV1 was 3.3 times higher on average than for the Ancylus Nephrops trawl (data not shown), i.e., similar to the value predicted from the swept area calculation (2.9; Table A1).

While standardization of the catches to swept areas does improve CPUE comparability, it does not address gearspecific differences in selectivity (Knijn et al. 1993). CPUE information derived from different vessels, trawls and mesh sizes may be biased due to differences in the size at full selectivity, even if a single species is considered (Gunderson 1993; Knijn et al. 1993; Rijnsdorp et al. 1996; Harley and Myers 2001). CPUE was estimated using only individuals larger than the first length class $(\mathrm{cm})$ that is fully selected by the largest mesh size (i.e., $80-\mathrm{mm}$ mesh cod end with the exception of a few hauls in 1947) used during the entire time series (Table A1) to substantially reduce inconsistencies related to the gear selectivity. For plaice, this was estimated to be around $16 \mathrm{~cm}$ total length (Wileman 1988). We assumed that all individuals above this size are equally vulnerable to the different gears used in the survey. This analysis is a review of several studies based on formal selectivity trials conducted with an experimental trawl and analyzing retention rates in the codend in relation to a control population.

Estimation of spawning stock biomass, recruitment and average maximum length

For each haul, spawning stock biomass (SSB) was estimated as the CPUE of females at or larger than the female size at $50 \%$ maturity $\left(L_{50 \%}\right)$ of $25 \mathrm{~cm}$ (Nielsen et al. 2004). Length-frequency data were converted to biomass using an annual length-weight relationship estimated from data collected on IBTS since 1981 (data not shown). Individual weight data were not available for the years before 1981, so an average of the parameter values for 1981-2007 was used. Recruitment (R) was estimated as individuals between 16 and $20 \mathrm{~cm}$ of length, which mostly corresponds to age 2 . Yearly average maximum length $\left(L_{\max }\right.$, in $\left.\mathrm{cm}\right)$ was defined as the mean of the observed maximum length between hauls and was consequently not affected by haul standardization procedures. $L_{\max }$ is usually considered as a robust proxy for evaluating the conservation status of a fish population because intensive exploitation removes the 
older and larger individuals (Piet and Jennings 2004; Bailey et al. 2008; Cardinale et al. 2009).

Statistical analysis

\section{Generalized additive model}

A generalized additive model (GAM, Hastie and Tibshirani 1990) was used to standardize CPUE (SSB, R) to account for the unstandardized design in the sampling among years, months, latitudes, longitudes and depths (see Maunder and Punt 2004 for a useful review of different standardization approaches). GAMs offer the advantage of being able to model the non-linearity that often relates biological data to environmental factors. This flexibility in modeling complex interactions makes GAMs a useful tool for exploratory analyses where conventional linear procedures have failed (Swartzman et al. 1992; Megrey et al. 2005). The general form of a GAM is:

$g(m)=a+\sum_{j=1}^{p} f_{j}\left(X_{j}\right)+\varepsilon$

where $m=E\left(Y / X_{1}, \ldots, X_{p}\right)$ is the expectation that the response variable $Y$ is related to the covariates $\left(X_{1}, \ldots, X_{p}\right)$ by the additive predictor $a+\sum f_{j}\left(X_{j}\right)$ and $\varepsilon$ is the random error.

Inspection of the distribution of CPUE (SSB, R) reveals a large number of low values, including true zeroes, but also occasional large catches. This is a common feature of ecological datasets (Martin et al. 2006). Statistical inference based on such data is likely to be spurious or wrong unless an appropriate distribution is chosen for the errors. We used a quasi-Poisson distribution (Minami et al. 2007) with variance proportional to the mean and a log-link function to constrain the estimates to be positive. The quasi-likelihood approach assumes that the scale parameter $\Phi$ of the distribution is unknown and can consequently account for more over-dispersion than the classical Poisson distribution (Wood 2006).

Different smoothing functions have been used for the explanatory variables. An isotropic smooth, the thin plate regression spline was adopted for modeling the effect of the interaction between latitude and longitude because of its appropriateness for modeling variables measured on the same scale as geographic coordinates (Wood 2006). A cyclic cubic regression spline was chosen to smooth the month predictor because it forces the smoothing to have the same value and first few derivatives at its initial and final points. The other predictors were modeled using the thin plate smoothing spline function (Wood 2004).

Inspection of the distributions for $L_{\max }$ and $L_{\text {mean }}$ revealed that these variables were normally distributed. Thus, a model specification as used for SSB and R was chosen to model $L_{\text {max }}$ and $L_{\text {mean }}$, but under the assumption of normality.

All the predictors and the interaction between latitude and longitude were included in the models, and a backward stepwise regression based on statistical significance and generalized cross validation (GCV; Wood 2001, 2004) was applied to find the best set of predictors and to select the final models. The least significant variable was excluded at each step of the backward stepwise regression. The GCV criterion allowed an optimal trade off between the amount of deviance explained by the model and the model complexity measured through the equivalent degrees of freedom. Thus, the selection of the smoothing parameters for each term was done using the measure of the global GCV for the model to balance fitting and smoothing the data. The maximum number of knots was limited for the smooth month and depth $(k=4)$ and for the interaction between latitude and longitude $(k=20)$ to simplify the interpretation of the results. The predicted year effect (mean and 1st and 3rd quartile), after scaling out the effects of the other predictors, was estimated from the final models. Residuals were analyzed using graphical methods (Cleveland 1993) for homogeneity of variance, violation of normality assumptions and departures from the model assumptions or other anomalies in the data and in the model fit. A sensitivity analysis on how the model predictions are affected by the size of the dataset was performed to evaluate the stability and robustness of the results, and to understand the reliability of the model to capture the underlying process described by the data (see ESM for methods details and results) The analyses were performed using the R library mgcv (Wood 2001; http://www.r-project.org).

\section{Accounting for changes in catchability}

As an indicator of stock abundance, CPUE relies on the assumption that catchability is constant over time. Although changes in catchability have seldom been estimated for survey data (Marchal et al. 2003), we examined the effect of changes in catchability on the estimates of the long-term trend in SSB and R using a power function with a simulated increase in catching efficiency (TC; technological creep) of 1, 2 and $3 \%$ per year. TC was applied until 1974, when modern fully standardized IBTS surveys started. From 1974 and onwards TC was considered null (although see Marchal et al. 2003) as the survey was conducted with the same vessel, engine, gear and sampling procedures.

\section{Mortality estimation}

The base model used in this analysis was derived by Gedamke and Hoenig (2006), and consists of a transitional 
form of a mean length mortality estimator for application in non-equilibrium conditions. The Beverton and Holt mortality estimator $(1956,1957)$ :

$Z=\frac{K\left(L_{\infty}-\bar{L}\right)}{\bar{L}-L_{c}}$

has the same data requirements as in the new transitional form and, as such, the latter has the potential for widespread use. The only information required to obtain an estimate of total mortality $(Z)$ is the von Bertalanffy growth parameters $K$ and $L_{\infty}$, the so-called length of first capture (smallest size at which animals are fully vulnerable to the fishery and to the sampling gear), $L_{c}$, and the mean length $(\bar{L})$ of the animals above $L_{c}$. Unlike the Beverton and Holt (1956, 1957) mortality estimator and earlier modifications (such as in Ehrhardt and Ault 1992), the restrictive assumption of equilibrium conditions (i.e., mortality rate has been constant for a long enough time period that the observed mean length reflects the current mortality rate) is not a requirement of the Gedamke and Hoenig (2006) approach.

The methodology and a practical application are described in detail in Gedamke and Hoenig (2006), and the method will only be described briefly here. The nonequilibrium formulation was derived by including multiple integrals to account for the different mortality histories experienced by fish of different ages. Assuming one change in mortality has occurred, for example, one integral represents fish recruited to the population after a change in mortality (i.e., these animals have experienced only the most recent mortality rate), and a second integral represents animals recruited before the change in mortality (i.e., these fish have experienced both the old and new mortality rates). After integration and simplification (see Appendix 1 in Gedamke and Hoenig 2006), an equation results in which the mean length in a population can be calculated $d$ years after a single permanent change in total mortality from $Z_{1}$ to $Z_{2}$ year $^{-1}$ :

$\bar{L}=L_{\infty}-\frac{Z_{1} Z_{2}\left(L_{\infty}-L_{c}\right)\left\{Z_{1}+K+\left(Z_{2}-Z_{1}\right) \exp \left(-\left(Z_{2}+K\right) d\right)\right\}}{\left(Z_{1}+K\right)\left(Z_{2}+K\right)\left(Z_{1}+\left(Z_{2}-Z_{1}\right) \exp \left(-Z_{2} d\right)\right)}$.

This extension requires only a series of mean lengths above a user-specified minimum size and the von Bertalanffy growth parameters. It can therefore be applied in many data-poor situations. This equation can also be generalized to allow for multiple changes in mortality rate over time (see Appendix 2 in Gedamke and Hoenig 2006). A maximum likelihood framework is then used to estimate $Z_{1}, Z_{2}$, and the year of change (alternatively $d$ ) from the observed mean lengths.

For this study, the model was implemented in $\mathrm{AD}$ Model Builder (version 7.1.1, Otter Research Ltd. 2004), which allowed for an unlimited number of changes in mortality. AIC (Akaike 1973) was used for model selection (Burnham and Anderson 2002). Initially, the model involved a single change in mortality. Additional changes in mortality were included in the model (which added two parameters-year of change and the new mortality rate) until the AIC values began to show limited improvement.

Annual mean length estimates were calculated using a GAM model using only individuals larger than $16 \mathrm{~cm}$ [as those are considered as fully selected by the gears used in the surveys; see Standardization of catch per unit effort (CPUE) and Generalized Additive Model for details]. The von Bertalanffy parameters were estimated from 18,173 fish that were aged between 1981 and 2007. The growth parameter $(K)$ was estimated to be 0.107 year $^{-1}(95 \% \mathrm{CI}$ $0.094-0.134$ year $\left.^{-1}\right)$ and $L_{\infty}$ to be $54.9 \mathrm{~cm}(95 \%$ CI 50.8 $56.7 \mathrm{~cm}$ ). Mean values were used as our base case scenario, and confidence limits were utilized in the sensitivity analysis. An additional scenario was constructed with a $K=0.25$ year $^{-1}$ and $L_{\infty}=47.3 \mathrm{~cm}$ as reported by Rijnsdorp and Ibelings (1989), although the $L_{\infty}$ is lower than a large number of the plaice observed in our population.

\section{Results}

Historical trends in SSB, R, average yearly $L_{\text {max }}, L_{\text {mean }}$, $Z$ and landings

The analysis included 5,416 survey tows conducted for 86 years from 1901 to 2007 (Fig. 1). The entire dataset comprised 14 vessels and 38 styles and modifications (i.e., dimension of headline, sweeps and mesh size) (Table A1) of a basic trawl design.

All covariates were estimated to be significant for the SSB, R, $L_{\max }$ and $L_{\text {mean }}$ GAM analyses, while year and depth generally explained the largest part of the deviance except for SSB (Table 1 and Table A2 in ESM). The full model that included all of the initial predictors achieved the lowest GCV for SSB, R, $L_{\max }$ and $L_{\text {mean }}$, and was preferred over models with higher GCV and a reduced set of variables (Table A2). Details of some of the alternative models for SSB, R, $L_{\max }$ and $L_{\text {mean }}$ are presented in Table A2. The final models were able to significantly reduce the total deviance, explaining up to about $57.7 \%$ of the deviance. Estimates of SSB and R assuming a constant increase in catchability of $1 \%$ annually were the baseline scenario. All tested scenarios are presented in Fig. 2, including the scenario with no increase in catchability. When a larger TC was assumed, the current estimates of SSB would only be between 10 and $20 \%$ of the maximum observed biomass, and the large year classes in the 1950s are comparable with those observed in the last decade (Fig. 2). 
Fig. 1 Map of study area with the locations of the hauls conducted and used in the analysis

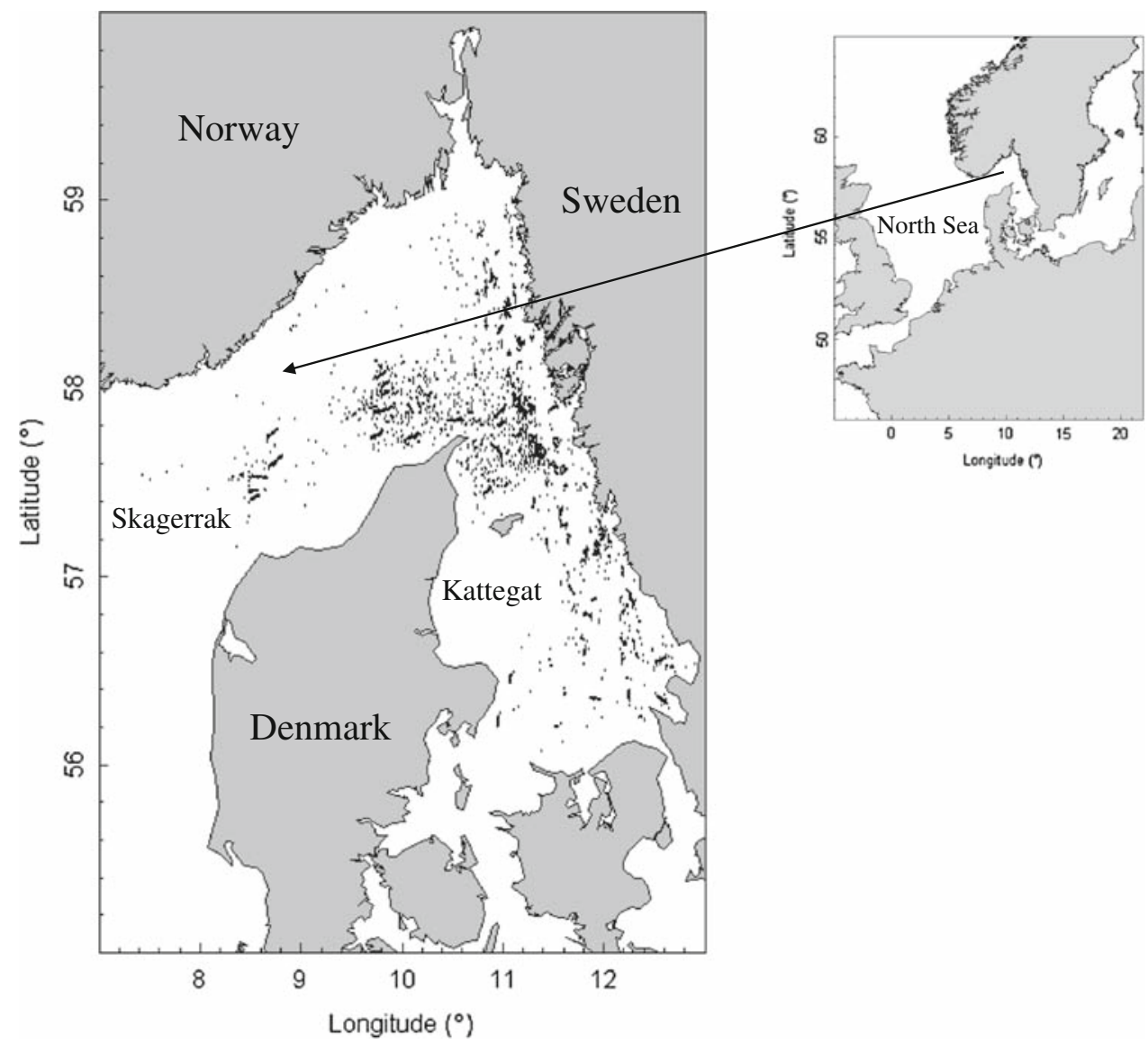

Table 1 Summary of final GAM models used to estimate spawning stock biomass (SSB), recruitment (R), average maximum length $\left(L_{\text {max }}\right)$ and average length $\left(L_{\text {mean }}\right)$ of plaice in the Kattegat-Skagerrak

\begin{tabular}{|c|c|c|c|c|c|c|c|}
\hline \multicolumn{4}{|c|}{ GAM: Quasi Poisson distribution with log-link } & \multicolumn{4}{|c|}{ GAM: Normal distribution with log-link } \\
\hline$d f$ & Variable & $F$ & $P$ & $d f$ & Variable & $F$ & $P$ \\
\hline \multicolumn{2}{|c|}{ Response: SSB } & \multicolumn{2}{|c|}{$n=5,416 ; \mathrm{DEV}=30.2 \%$} & \multicolumn{2}{|c|}{ Response: $L_{\max }$} & \multicolumn{2}{|c|}{$n=3,462 ; \mathrm{DEV}=24.2 \%$} \\
\hline 8.9 & Year & 44.5 & $<0.0001$ & 8.7 & Year & 63.7 & $<0.0001$ \\
\hline 8.9 & Latitude & 17.0 & $<0.0001$ & 5.9 & Latitude & 2.7 & 0.004 \\
\hline 8.8 & Longitude & 18.1 & $<0.0001$ & 7.4 & Longitude & 3.5 & $<0.0002$ \\
\hline 1.9 & Month & 69.8 & $<0.0001$ & 1.3 & Month & 3.8 & 0.022 \\
\hline 1.0 & Depth & 48.3 & $<0.0001$ & 2.3 & Depth & 18.5 & $<0.0001$ \\
\hline 16.9 & Latitude:longitude & 20.9 & $<0.0001$ & 16.9 & Latitude:longitude & 4.8 & $<0.0001$ \\
\hline \multicolumn{2}{|c|}{ Response: $\mathrm{R}$} & \multicolumn{2}{|c|}{$n=5,416 ; \mathrm{DEV}=57.7 \%$} & \multicolumn{2}{|c|}{ Response: $L_{\text {mean }}$} & \multicolumn{2}{|c|}{$n=3,824 ; \mathrm{DEV}=52.3 \%$} \\
\hline 8.4 & Year & 101.7 & $<0.0001$ & 8.7 & Year & 258.1 & $<0.0001$ \\
\hline 8.9 & Latitude & 15.4 & $<0.0001$ & 5.9 & Latitude & 3.7 & $<0.0001$ \\
\hline 8.6 & Longitude & 17.2 & $<0.0001$ & 7.4 & Longitude & 3.7 & $<0.0001$ \\
\hline 1.9 & Month & 59.0 & $<0.0001$ & 1.3 & Month & 22.1 & $<0.0001$ \\
\hline 2.7 & Depth & 88.4 & $<0.0001$ & 2.3 & Depth & 70.2 & $<0.0001$ \\
\hline 16.9 & Latitude:longitude & 24.7 & $<0.0001$ & 16.9 & Latitude:longitude & 6.4 & $<0.0001$ \\
\hline
\end{tabular}

Year, latitude, longitude, month, depth and the interaction between latitude and longitude are predictive factors included in the initial models. DEV is the total deviance explained by the final model, $n$ is the number of hauls

Assuming a TC of $1 \%$, SSB decreased from the beginning of the century until the 1940s (i.e., WWII; Fig. 2a). The stock started to recover during WWII, reaching a peak during the 1960s, and then declined rapidly until the middle of the 1970s. Since then, a steady increase in SSB has been discernable. The biomass in 2007 is about $37 \%$ of 

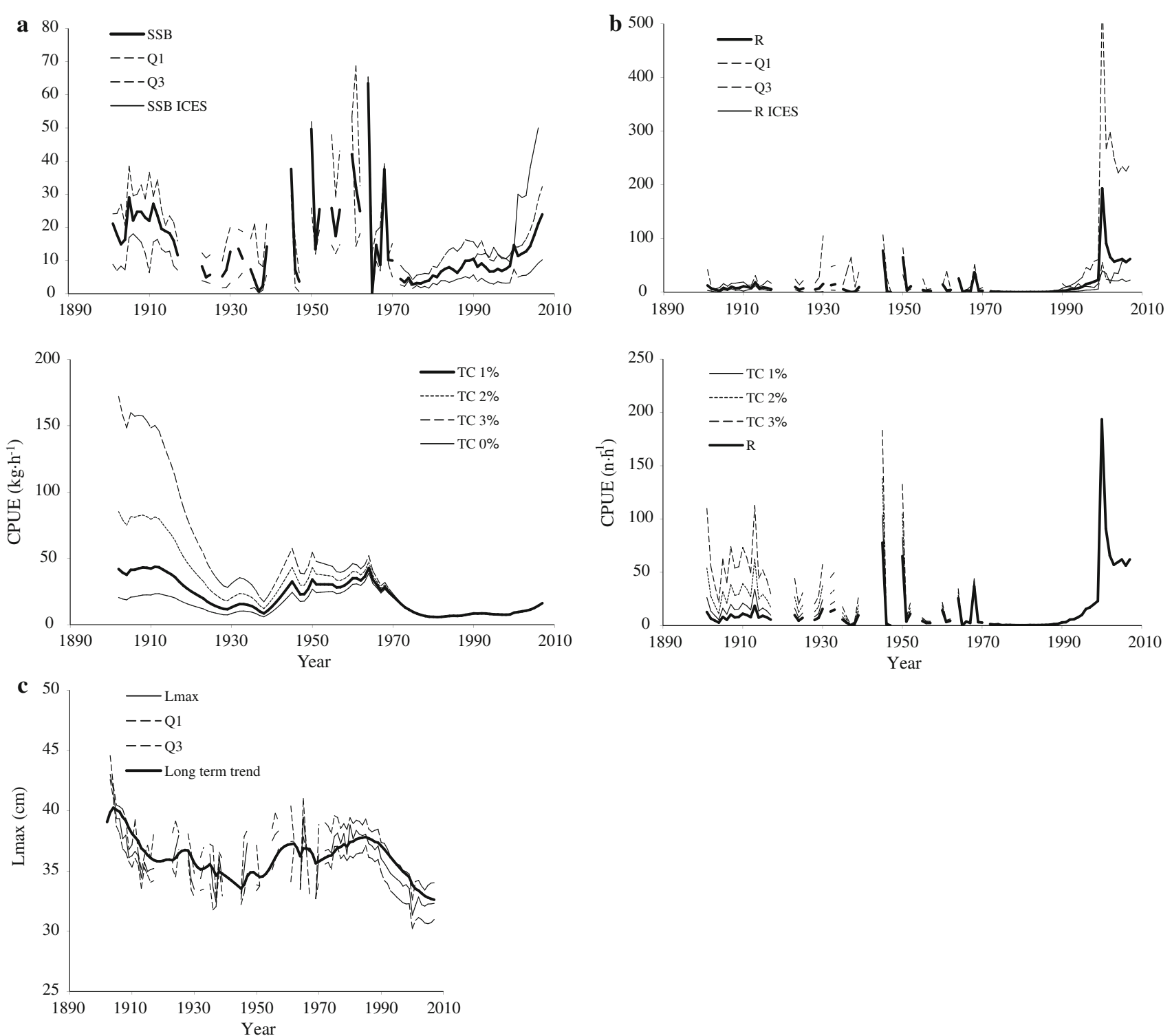

Fig. 2 Historical trend of a spawning stock biomass (SSB) (long time trend after exponential smoothing), $\mathbf{b}$ recruitment $(R)$ and $\mathbf{c}$ yearly average maximum length $\left(L_{\max }\right)$ (long time trend after exponential smoothing) with mean, 1st and 3rd quartile (Q1, Q3). Effect of including an increased catching efficiency $(T C)$ on the estimates of $S S B$ and $R$ was estimated using a power function with 1, 2 and 3\%

the initial level and about $38 \%$ of the maximum biomass. Uncertainty around the mean SSB estimates is relatively small, except in the 1950s and 1960s.

The recruitment curve is rather fragmented, but nonetheless indicates a rather episodic recruitment pattern (Fig. 2b). Two large year classes appeared just after WWII, and recruitment has been very high during the last 10 years of the time series. The 1998 and 1999 year classes are by far the largest observed in the time series and are likely to be the main reason for the recent observed increased stock biomass (Fig. 2a). However, the uncertainty around the R

increase per year applied to the long-term trend for SSB. The same catching efficiency was assumed from 1974 and onwards (see text for details). ICES estimates of SSB and $R$ are in a different scale than original data for an easier comparison with our estimates. See ICES (2007) for details

estimates for the 1999 and later year-classes is greater than for the earlier estimates.

Average annual $L_{\max }$ (Fig. 2c) declined from the beginning of the century with a clear pattern of recovery during WWII that continued to the middle of the 1980s. However, $L_{\max }$ declined substantially thereafter. The total decrease over the century is about $10 \mathrm{~cm}$, of which approximately $40 \%$ has occurred since the middle of the 1980s.

$L_{\text {mean }}$ also increased during WWII, and a pronounced decline started after 1980 (Fig. 3a). The mean length 
analysis indicated that there was enough information in the data to estimate seven changes in mortality rates (16 parameters; Table A3 in ESM, Fig. 3b). The sensitivity to alternative von Bertallanffy parameters showed very similar patterns in changes in mortality compared to the baseline scenario, but the absolute values of each model differed slightly (Fig. 3b).

Total landings (Fig. 4) fluctuated at a constant level until the onset of WWII. A rapid increase in landings occurred at the end of the 1950s. Landings declined continuously from the middle of the 1970s until the most recent years. Landings did not include discard as no information is available on the absolute or relative magnitude of discards for this stock.

The trends in SSB and R in our study are fairly consistent with the ICES age-based SURBA assessment
(1990-2006; see ICES 2007 for details; Fig. 2a, b) in estimating a series of large year-classes and increases in SSB in recent years. Nonetheless, the 1999 and 2000 are relatively much larger than estimated by the ICES assessment. Series of sensitivity analyses were performed in the study by estimating recruitment using different length ranges $(17-21$ to $20-24 \mathrm{~cm})$ or just using oceanic hauls (i.e., excluding coastal hauls). Although the trends were similar and thus the conclusions regarding an increasing trend in recruitment is unchanged, the exclusion of the coastal hauls reduced the increase in $\mathrm{R}$ in the last years and the time-series of $\mathrm{R}$ estimates was more similar to the ICES estimates (ICES 2007). The same did not apply for the trend in $Z$ that is stable according to ICES estimates but has been increasing since the 1980s according to our analysis (Fig. 4). Nevertheless, the ICES analysis suggests very
Fig. 3 a Observed, predicted and mean length residuals for the base case scenario $\left(K=0.107\right.$ year $^{-1}$ and $\left.L_{\infty}=54.9 \mathrm{~cm}\right)$. b Estimated mortality rates for the base case and sensitivity analysis to different von Bertalanffy $(V B F)$ growth parameters: high VBF $\left(K=0.094\right.$ year $^{-1}$ and $\left.L_{\infty}=56.6 \mathrm{~cm}\right)$, low VBF $\left(K=0.134\right.$ year $^{-1}$ and $L_{\infty}=50.8 \mathrm{~cm}$ ), and as in Rijnsdorp and Ibelings (1989; $K=0.25$ year $^{-1}$ and $\left.L_{\infty}=47.3 \mathrm{~cm}\right)$. Annual total mortality estimates from the ICES assessment (ICES 2007) are also indicated
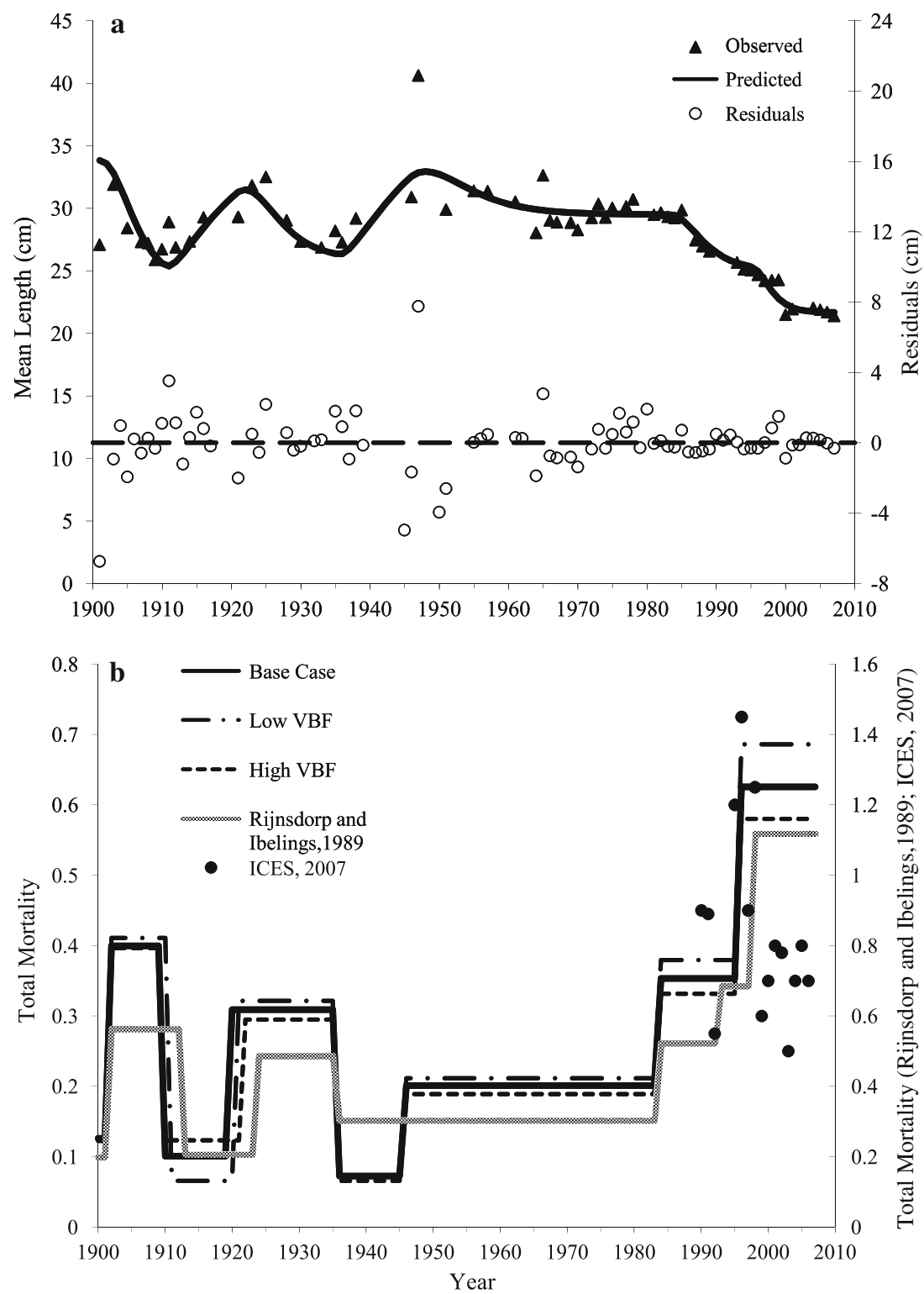


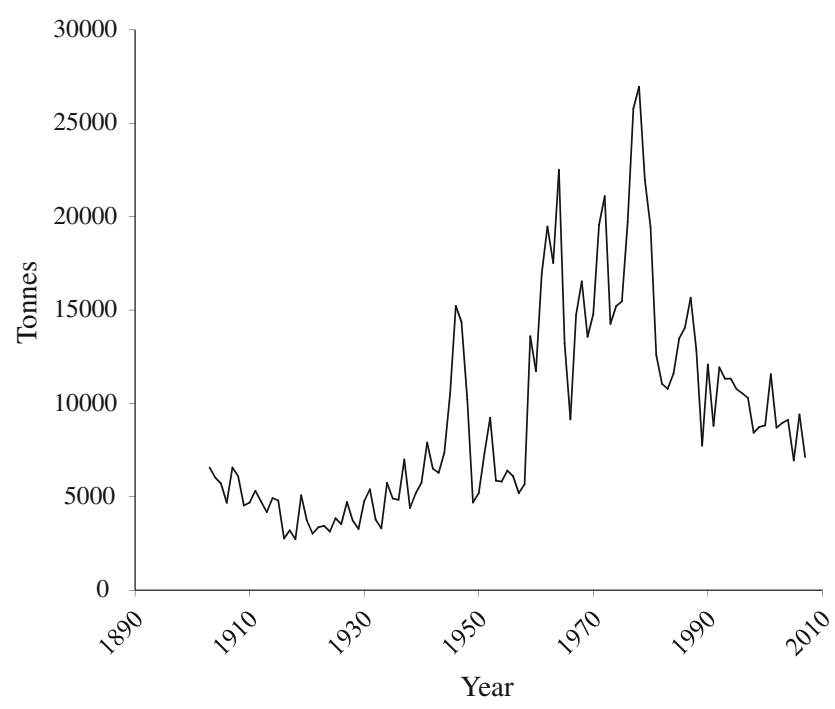

Fig. 4 Historical trend of total landings of plaice from the KattegatSkagerrak since 1902 as collected from official ICES estimates. Discards are not included

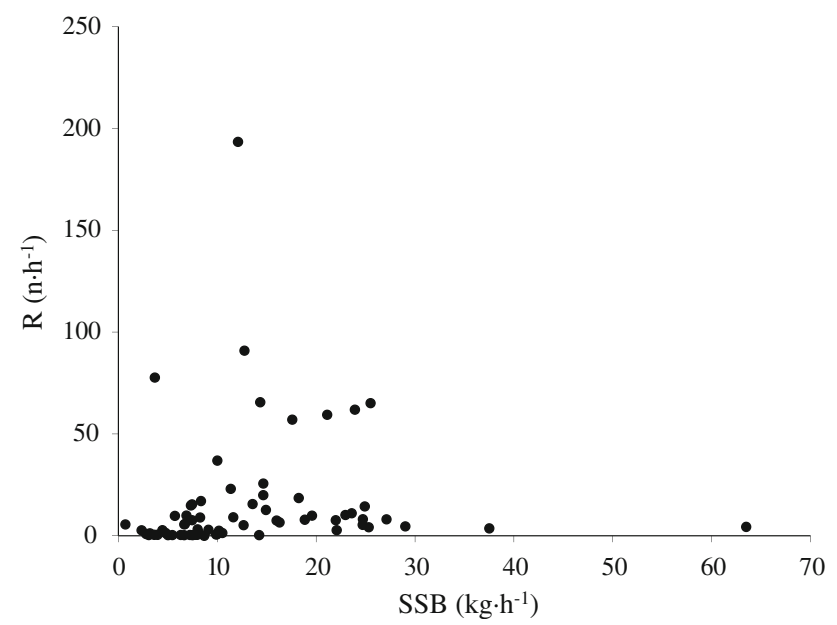

Fig. 5 Relationship between stock and recruitment for plaice from the Kattegat-Skagerrak. Spawning stock biomass $(S S B)$ is estimated using individuals larger than $25 \mathrm{~cm}$; recruitment $(R)$ is calculated using fish between 15 and $20 \mathrm{~cm}$. See text for details

similar estimates of total mortality for recent years $(0.6-$ 0.8 year $^{-1}$ ). Finally, the plot of the SSB and recruitment data (Fig. 5) showed a typical Ricker curve relationship, with the largest year classes produced at intermediate levels of SSB.

\section{Discussion}

A historical perspective is fundamental for estimating biological reference points for the management of exploited fish populations. Only referring to the recent past when evaluating the present situation can result in a "shifting baseline syndrome" (Pauly 1995), i.e., unexploited conditions regarding biomass, productivity and biodiversity may be drastically underestimated. The initiation and broad expansion of the steam-trawler fleet in the North Sea during the late 1800s has been blamed for the depletion of several demersal fish stocks, including plaice (Blegvad 1943). The increased effort resulted in a reduction of commercial CPUE of plaice (and presumably of other stocks as well) by a factor of 5 (Rijnsdorp and Millner 1996) in a few decades. Nowadays, as exploitation of living resources in the North Sea has already been going for centuries, it is likely that less than $5 \%$ of the total biomass of fish is left compared to a pristine situation (Roberts 2007). In that context, it is important to stress that the beginning of the 1900s represents only a waypoint rather than a baseline from which it is possible to fully estimate the decline of fish populations in the North Sea (Roberts 2007).

The plaice stock declined steadily until the start of WWII in the eastern part of the North Sea, where trawl fisheries intensified at the beginning of the 20th century following the introduction of otter trawling. The decline in adult biomass was accompanied by a decrease in average length. A plausible explanation for this decrease is that the lightly exploited population at the beginning of the last century consisted of the so-called "accumulated biomass" of very old, large individuals, which were rapidly fished out when trawl fisheries expanded. The stock recovered rapidly after WWII, reaching the largest observed biomass during the 1960s. The recovery is likely to have been boosted by the emergence of two very large year classes in 1945 and 1950. However, a rapid decrease in stock size has occurred from the mid-1960s. The trend in SSB generally matches available estimates of landings, although official reported landings are in fact higher at the end of the time series, likely related to a much higher exploitation level in the more recent years.

We utilized research survey data to develop a standardized historical time series of relative biomass, abundance and average individual size of the commercially important plaice stocks in the Kattegat-Skagerrak. Historical survey data, when available, might provide reliable estimates of baseline conditions for the management of commercial fish populations. As the time series extended back to the beginning of the last century and comprised over 5,400 hauls during a 107-year period of time, standardization was required to account for different research protocols. We have utilized as much of the available information as possible and explored several sensitivity analyses to develop a time series longer than 100 years. We chose to use our approach rather than classic population models because we do not have the catch-at-age data 
required for a traditional VPA analysis. Instead, our approach is simple because we did not make any a priori assumption about the population dynamics. Use of an error distribution that can account for a high number of both zeroes and incidentally high catch-rates led to reconstructed trends that were robust to differences in underlining model assumptions. The sensitivity analyses also demonstrated that final model estimates were very similar when the models were built using a year-stratified random sub-sample of the available hauls. Although some selectivity issues still exist (i.e., how the catchability of different size classes varies with the speed of the vessel or the type of trawl), our approach appears to be fairly robust to uncertainty.

The plaice stock in the Kattegat-Skagerrak was considered as recently as 2004 (Nielsen et al. 2004) to be severely overexploited and suffering from reduced recruitment. Those assertions were based on estimates from an age-based assessment model (XSA), reduced lengthand age-at-maturity, and low numbers of large fish (>30 cm; Svedäng et al. 2002) in the catches. However, questions regarding catch allocation and misreporting have resulted in rejection of the fishery-dependent virtual population analysis since 2006, so there is currently no accepted stock assessment. Thus, survey indices were chosen to describe the trend from 1990 onward (ICES 2007). Our work extends the available time series so that the evaluation of trend is more informative. Our data show that the biomass of adult plaice in the Skagerrak-Kattegat has increased considerably over the last decade as a result of several year classes, which are as large as those seen in the 1950s. Our adult biomass index is based on individuals larger than $25 \mathrm{~cm}$, which means that this recent increase would be reduced (biomass in 2007 would be $20 \%$ instead of $34 \%$ of the maximum observed adult biomass) if a larger threshold was used $(>30 \mathrm{~cm}$, data not shown). Hence, the adult stock is currently large, but likely comprised of mainly first time spawners derived from recent large year classes, observations that generally match with surveybased assessments made by ICES (2007). Also, the stock and recruitment data show a pattern typical of a Ricker curve, with the largest year classes produced at intermediate levels of spawning biomass.

The estimated total mortality rate is 2.6 times higher than that observed from the beginning of the last century until 1985 and, assuming a constant $\mathrm{M}$ equal to 0.2 year $^{-1}$ (ICES 2007), higher than any candidate proxy of $F_{\text {msy }}$ as derived from the neighboring North Sea plaice stock $\left(F=0.12-0.30\right.$ year $^{-1}$ ) (ICES 2007). The Gedamke and Hoenig (2006) approach has proven useful to estimate mortality rates for a number of periods. However, recruitment trends need to be taken into consideration when interpreting model results. Large recruitment appeared periodically during the time series, although no obvious trend was observed until the last few decades. Although the Gedamke and Hoenig (2006) model assumes 'constant' recruitment, it is robust to variability in recruitment, and only the trends (i.e., non-stationarity) in the most recent time period are potentially problematic. A violation of the stationarity assumption can result in a biased estimate of mortality (e.g., an increasing trend in recruitment results in an overestimate of mortality). It is also important to note that changes in $\mathrm{R}$ over the entire series are less problematic because $Z$ is estimated for several different time periods. While the large spike in recruitment, which occurred in the recent decade, may lead to some uncertainty in the absolute estimates of total mortality for this time period, it is important to note that the model has only been estimating a single mortality rate since 1995 . Since $1995, \mathrm{R}$ increased until 2000 and then declined for a few years, resulting in opposing trends and opposite potential biases. Nonetheless, recruitment has generally increased since 1995, and the most recent mortality rate is likely to be slightly overestimated. However, the overall conclusions regarding an increasing trend in $Z$ since 1985 would remain unchanged. The presence of this longer scale increasing trend in $Z$ is also supported by the decreasing trend in the maximum observed length and is in agreement with various ICES Working Group reports (Sparholt et al. 2007), which state that $F$ has generally increased during the second half of the century for North Sea stocks. Our results for the most recent years are also in agreement with the most recent ICES assessment, which reports that mortality rates have been relatively high in the last decade without any particular trend (ICES 2007).

While large recruitment of plaice has been indicated in the latest assessment (ICES 2007), such a trend was unforeseen on the time scale of a century. A partial explanation might be a decrease (around 10\% in the last decade; data not shown) of the average length of the juveniles that can cause overlap with adjacent age classes when a specific length class is used to infer recruitment. However, such a decrease has a very limited power to explain the large recruitment events (up to 20-fold) observed during the last 15 years. Our inclusion of the Ancylus coastal survey, which is not used in the ICES assessment, might in part explain the difference in magnitude between our estimates and the ICES estimates given that juvenile plaice are mainly concentrated along the coastal, shallow areas of Sweden (Phil et al. 2005). Although the magnitude of increase in recruitment is uncertain, all available information suggests that large year classes have been relatively common in the last 15 years. In this context, several hypotheses could be put forward to explain the enhanced recruitment in recent years, including the effects of increased water temperature (Rayner et al. 
2003), released predation mortality on juvenile plaice due to a reduction in cod abundance (Svedäng and Bardon 2003; Cardinale and Svedäng 2004; ICES 2007) or increased available prey biomass due to trawling (Hiddink et al. 2008). However, a formal analysis of the contribution of the different effects on recruitment is beyond the scope of this study. Regardless of the uncertainty in the magnitude of the large year classes observed in the last decade, our results and interpretation of available information do not support the hypothesis that coastal habitat deterioration results in a decrease of plaice recruitment along the Swedish west coast, (Phil et al. 2005, 2006). The large year classes observed in the last few years suggest that deterioration of coastal habitat does not represent a limiting factor for recruitment of plaice as is presently advocated (e.g., Wennhage et al. 2007).

Overall, our analyses extend the available time series by over 80 years and provide managers with a historical perspective of the stock that will help in making decisions for the long-term management of plaice in the Kattegat-Skagerrak. Reconstruction of historical time series, especially if derived from survey data, is beneficial to improve our ability to attain sustainable resource exploitation in marine areas, and results can be used to set baselines for long-term management. Also, reconstructed historical time series of biomass, recruitment and individual size are essential for comparing climate, habitat and fisheries effects on exploited fish populations.

\section{References}

Akaike H (1973) Information theory and an extension of the maximum likelihood principle. In: Petrov BN, Csaki F (eds) Second international symposium on information theory. Akademiai Kiado, Budapest, pp 267-281

Andersson KA (1954) Fiskar och Fiske i Norden. Bokförlaget Natur och Kultur, Stockholm (in Swedish)

Bailey KM (2000) Shifting control of recruitment of walleye pollock Theragra chalcogramma after a major climatic and ecosystem change. Mar Ecol Progr Ser 198:215-224

Bailey KM, Barret GJ, Craig O, Milner N (2008) Historical ecology of the North Sea Basin. In: Rick TC, Erlandson JM (eds) Human impact on ancient marine ecosystems: a global perspective. University of California Press, Berkeley and Los Angeles, California, pp 215-242

Beverton RJH, Holt SJ (1956) A review of methods for estimating mortality rates in fish populations, with special reference to sources of bias in catch sampling. Rapp Proces-verb Reun Cons Int Explor Mer 140:67-83

Beverton RJH, Holt SJ (1957) On the dynamics of exploited fish populations. UK Ministry of Agriculture, Fisheries, Food, and Fishery Investigations Series II, vol XIX

Blegvad H (1943) Fiskeriet I Danmark. Selskabet for udgivelse af Kulturskrifter, Copenaghen (in Danish)
Burnham KP, Anderson DR (2002) Model selection and multimodel inference: a practical information-theoretic approach, 2nd edn. Springer-Verlag, New York

Cardinale M, Svedäng H (2004) Modelling recruitment and abundance of Atlantic cod, Gadus morhua, in the Kattegat-eastern Skagerrak (North Sea): evidence of severe depletion due to a prolonged period of high fishing pressure. Fish Res 69:263-282

Cardinale M, Linder M, Bartolino V, Maiorano L, Casini M (2009) Conservation value of historical data: reconstructing stock dynamics of turbot during the last century in the KattegatSkagerrak. Mar Ecol Prog Ser 386:197-206

Cleveland WS (1993) Visualizing data. Hobart Press, Summit, NJ

Daan N, Gislason H, Pope JG, Rice J (2005) Changes in the North Sea fish community: evidence of indirect effects of fishing? ICES J Mar Sci 62:177-188

Ehrhardt NM, Ault JS (1992) Analysis of two length-based mortality models applied to bounded catch length frequencies. Trans Am Fish Soc 121:115-122

Fromentin JM, Kell LT (2007) Consequences of variations in carrying capacity or migration for the perception of Atlantic blufin tuna (Thunnus thinnus) population dynamics. Can J Fish Aquat Sci 64:827-836

Gedamke T, Hoenig JM (2006) Estimation of mortality from mean length data in non-equilibrium situations, with application to monkfish (Lophius americanus). Trans Am Fish Soc 135:476-487

Gunderson DR (1993) Surveys of fisheries resources. Wiley, New York

Harley SJ, Myers RA (2001) Hierarchical Bayesian models of lengthspecific catchability of research trawl survey. Can J Fish Aquat Sci 58:1569-1584

Hasslöf O (1949) Svenska västkustfiskarna: Studier i en yrkesgrupps näringsliv och sociala kultur. Skrifter utgivna av bohusläns museum och Bohusläns hembygdsförbund. Nr 18. Risbergs tryckeri $\mathrm{AB}$, Uddevalla (in Swedish)

Hastie T, Tibshirani R (1990) Generalized additive models. Chapman and Hall, London

Hiddink JG, Rijnsdorp AD, Piet G (2008) Can bottom trawling disturbance increase food production for a commercial fish species? Can J Fish Aquat Sci 65:1393-1401

ICES (1992) Manual for international bottom trawl surveys, revision IV. ICES CM 1992/H:3/Addendum

ICES (2007) Report of the ICES Advisory Committee on Fishery Management, Advisory Committee on the Marine Environment and Advisory Committee on Ecosystems. ICES Advice. Books, pp $1-10$

Jackson JBC, Kirby MX, Berger WH, Bjorndal KA, Botsford LW, Bourque BJ, Bradbury RH, Cooke R, Erlandson J, Estes JA, Hughes TP, Kidwell S, Lange CB, Lenihan HS, Pandolfi JM, Peterson CH, Steneck RS, Tegner MJ, Warner RR (2001) Historical overfishing and the recent collapse of the coastal ecosystem. Science 293:629-638

Knijn RJ, Boon TW, Heessen HJL, Hislop JRG (1993) Atlas of North Sea fishes. ICES Coop Res Rep 194:1-268

Köster F, Möllmann C, Hinrichsen H-H, Wieland K, Tomkiewicz J, Kraus G, Voss R (2005) Baltic cod recruitment: the impact of climate variability on key processes. ICES J Mar Sci 62:14081425

Lotze HK, Milewski L (2004) Two centuries of multiple human impacts and successive changes in a North Atlantic food web. Ecol Appl 14:1428-1447

Mackinson S (2002) Representing trophic interaction in the North Sea in the 1880 s using the Ecopath massbalance approach. In: Guénette S, Christensen V, Pauly D (eds) Fisheries impacts on North Atlantic ecosystems: models and analyses. Fish Centre Res Rep 9(4), pp 35-98 
Marchal P, Ulrich C, Korsbrekke K, Pastoors M, Rackham B (2003) Annual trends in catchability and fish stock assessment. Sci Mar 67(Suppl 1):63-73

Martin TG, Wintle AB, Rhodes JR, Kuhnert PM, Field SA, LowChoy SJ, Tyre AJ, Possingham HP (2006) Zero tolerance ecology: improving ecological inference by modelling the source of zero observations. Ecol Lett 8:1235-1246

Maunder MN, Punt AE (2004) Standardizing catch and effort data: a review of recent approaches. Fish Res 70:141-159

Megrey BA, Lee Y-W, Macklin SA (2005) Comparative analysis of statistical tools to identify recruitment-environment relationships and forecast recruitment strength. ICES J Mar Sci 62:1256-1269

Minami M, Lennert-Cody CE, Gao W, Roman-Verdesoto M (2007) Modelling shark by-catch: the zero-inflated negative regression model with smoothing. Fish Res 84:210-221

Myers RA, Worm B (2003) Rapid worldwide depletion of predatory fish communities. Nature 423:280-283

Nielsen E, Støttrup JG, Heilmann J, MacKenzie BR (2004) The spawning of plaice Pleuronectes platessa in the Kattegat. J Sea Res 51:219-228

Ojaveer H, MacKenzie BR (2007) Introduction: historical development of fisheries in northern Europe-reconstructing chronology of interactions between nature and man. Fish Res 87:102-105

Pauly D (1995) Anecdotes and the shifting baseline syndrome of fisheries. Trend Ecol Evol 10:430

Phil L, Modin J, Wennahage H (2005) Relating plaice (Pleuronectes platessa) recruitment to deteriorating habitat quality: effects of macroalgal blooms in coastal nursery grounds. Can J Fish Aquat Sci 62:1184-1193

Phil L, Baden S, Kautsky N, Ronnback P, Soderquist T, Troell M, Wennahage H (2006) Shift in fish assemblages structure due to loss of seagrass Zostera marina habitats in Sweden. East Coast Sci 67:123-132

Piet GJ, Jennings S (2004) Response of potential fish community indicators to fishing. ICES J Mar Sci 62:214-225

Rayner NA, Parker DE, Horton EB, Folland CK, Alexander LV, Rowell DP (2003) Global analyses of sea surface temperature, sea ice, and night marine air temperature since the late nineteenth century. J Geophys Res. doi:10.1029/2002JD002670

Rijnsdorp AD, Ibelings BW (1989) Sexual dimorphism in the energetics of reproduction and Growth of North sea plaice, Pleuronectus platessa L. J Fish Biol 35:401-415
Rijnsdorp AD, Millner RS (1996) Trends in population dynamics, exploitation of North Sea plaice (Pleuronectes platessa L.) since the late 1800s. ICES J Mar Sci 53:1170-1184

Rijnsdorp AD, van Leeuwen PI, Daan N, Hessen HJL (1996) Changes in abundance of demersal fish species in the North Sea between 1906-1909 and 1990-1995. ICES J Mar Sci 53:1054-1062

Roberts C (2007) The unnatural history of the sea. The past and the future of humanity and fisheries. Island Press, Washington

Rosenberg AA, Bolster WJ, Alexander KE, Leavenworth WB, Cooper AB, McKenzie MG (2005) The history of ocean resources: modelling cod biomass using historical records. Front Ecol 3(2):84-90

Sparholt H, Bertelsen M, Lassen H (2007) A meta-analysis of the status of ICES fish stocks during the past half century. ICES J Mar Sci 64:707-713

Svedäng H (2007) The Ancylus survey- an opportunity to enlarge fishery independent information to the Kattegat cod assessment. Working document presented at BIFS meeting in Rostock, Germany, with appendix

Svedäng H, Bardon G (2003) Spatial and temporal aspects of the decline in cod (Gadus morhua L.) abundance in the Kattegat and eastern Skagerrak. ICES J Mar Sci 60:32-37

Svedäng $\mathrm{H}$, Øresland V, Cardinale M, Hallbäck H, Jakobsson P (2002) De kustnära fiskbeståndens utveckling och nuvarande status vid svenska västkusten. Synopsis av "Torskprojektet steg I-III". Finfo 6

Swartzman GW, Huang GC, Kaluzny S (1992) Spatial analysis of Bering Sea groundfish survey data using generalized additive models. Can J Fish Aquat Sci 49:1366-1378

Wennhage H, Phil L, Stål J (2007) Distribution and quality of plaice (Pleuronectes platessa) nursery grounds on the Swedish west coast. J Sea Res 57:218-229

Wileman D (1988) Cod end selectivity; a review of available data. Final Report for the Commission of the European Communities, DG FISH. Danish Fisheries Technology Institute, Denmark

Wood SN (2001) mgcv: GAMs and generalized ridge regression for R. R News 1/2:20-25

Wood SN (2004) Stable and efficient multiple smoothing parameter estimation for generalized additive models. J Am Stat Assoc 99:673-686

Wood SN (2006) Generalized additive models: an introduction with R. Chapman and Hall/CRC, Florida 